\title{
Espacio: elemento central en los movimientos sociales por megaproyectos*
}

\author{
María Verónica Ibarra García
}

El artículo propone al espacio como una categoría analítica en cuatro movimientos sociales que se han desarrollado en el centro y sur de México, a partir de 1990. Este estudio se realiza desde la geografía política crítica. Se inicia con un recorrido del espacio como categoría desde esta ciencia desde siglo XIX hasta llegar a la visión crítica de la misma. Posteriormente, se identifica al espacio rural producido bajo el régimen priista. Se analizan los megaproyectos como un tipo de espacio que transforma de manera sustancial al espacio rural,y por último se examinan los cuatro movimientos sociales que manifiestan las transformaciones políticas que el espacio rural ha presentado.

PALABRAS CLAVE: espacio, poder, geografía política, megaproyectos, movimientos sociales

\section{Space: Central Element in Social Movements for Megaprojects}

This article proposes the space as an analytical category presented in four social movements developed in the central and southern Mexico, since 1990. This is a study of critical political geography, that is why it covers the historical development of the concept space since the political geography of the beginning of the XX century to its critical trend. Afterwards, the produced rural space is treated in the light of the Partido de la Revolución Institucional regime. Then, megaprojects are analyzed as a sort of space that has deeply transformed the rural space. Finally, it is presented how the four social movements show the political transformations produced in the rural space.

KEYWORDS: space, power, political geography, megaprojects, social movements

María Verónica Ibarra García: Universidad Nacional Autónoma de México, Distrito Federal, México maveroibar@gmail.com

Desacatos, núm. 39, mayo-agosto 2012, pp. 141-158

Recepción: 22 de mayo de 2009 / Aceptación: 30 de diciembre de 2009

\footnotetext{
* Una primera versión de este trabajo se presentó en el XII Encuentro de Geógrafos de América Latina en Montevideo, Uruguay, en la mesa "Respuestas teórico-metodológicas de la geografía ante las nuevas espacialidades", el 5 de abril de 2009.
} 


\section{INTRODUCCIÓN}

$\mathrm{M}$ éxico tiene una larga tradición de movimientos sociales. A partir de las dos últimas décadas del siglo xx y la primera del XXI han tenido lugar movilizaciones por parte de habitantes que se verían afectados por megaproyectos en los que la naturaleza presentaría cambios en su uso y propiedad. Los proyectos de transformación espacial han generado tensiones que en ocasiones se han convertido en movimientos sociales. Entre los más significativos ${ }^{1}$ se encuentran el de San Juan Tetelcingo, en el estado de Guerrero, en 1990, en oposición a la construcción de una hidroeléctrica; el de Tepoztlán, en el estado de Morelos, en 1994-1995, contra la construcción de un club de golf; de San Salvador Atenco, en 2001, en oposición a la construcción de la terminal aérea alterna de la ciudad de México, y el organizado por los ejidatarios y colonos habitantes de las márgenes del Río Papagayo, en el municipio de Acapulco, Guerrero, en 2003, en respuesta al proyecto de construcción de la hidroeléctrica La Parota.

Todos son movimientos sociales que han sido estudiados desde la ciencia política, la historia, la antropología, la sociología, la economía y los estudios rurales, disciplinas que tradicionalmente han trabajado estos temas. La geografía política mexicana los ha olvidado, no obstante es la ciencia que cuenta con instrumentos teórico-metodológicos que permiten enriquecer el análisis de estos movimientos sociales en retroalimentación con las disciplinas mencionadas. Éste es uno de los primeros trabajos realizados desde la geografía política crítica para el caso de México. Tiene por objetivo analizar la realidad política mexicana por medio de los movimientos sociales de

\footnotetext{
${ }^{1}$ La lista de estas movilizaciones locales y regionales es extensa. Aquí recuperamos estas cuatro por ser consecutivas, porque fueron visualizadas con mayor insistencia por la prensa nacional y porque cumplen con el objetivo de impedir la realización de los megaproyectos.
}

oposición a la producción de espacios hegemóni$\cos ,{ }^{2}$ recuperando el concepto de espacio.

El trabajo está organizado en cuatro apartados. Primero se analiza el concepto de espacio dentro de la tradición geográfica y se identifican las aportaciones metodológicas de la geografía política crítica. Enseguida se plantean los marcos teóricos más significativos en el estudio de los movimientos sociales. Posteriormente se observa el espacio rural bajo el régimen priista y se presentan los megaproyectos bajo la hegemonía del Partido Revolucionario Institucional (PRI). Se esbozan los cuatro movimientos sociales mencionados y se establecen las conclusiones.

\section{EL ESPACIO EN LATRADICIÓN GEOGRÁFICA}

\section{El espacio bajo la geografía tradicional}

En el siglo XIX, Friedrich Ratzel, en consonancia con su tiempo y bajo la influencia de los planteamientos darwinistas, propuso el concepto de espacio a la geografía, visualizado como espacio vital. Los postulados de este naturalista convertido en geógrafo respondían a la necesidad de relacionar el poder con el espacio, en el marco de la conformación del Estado alemán a finales del siglo xIx. Ése fue el inicio de la geografía en tanto que ciencia institucionalizada en Alemania y el de la geografía política como rama de la geografía humana. El desarrollo de la geopolítica ${ }^{3}$

\footnotetext{
2 Existe otra tendencia de análisis de estos problemas desde la geografía cultural, en la cual las nociones de territorio, territorialidad, cultura, arraigo e identidad son los elementos conceptuales que conducen el análisis. Sin embargo, éstos han sido recuperados más por la sociología (Giménez, 2001) que por la misma geografía mexicana.

${ }^{3}$ La denominada geopolítica clásica es racista, xenófoba y violenta. Es el soporte ideológico de gobiernos totalitarios. Por esta razón existe un debate en la geografía anglosajona principalmente ante el resurgimiento de los estudios de geopolítica dentro de la geografía, e incluso para deslindarse de esa tradición geopolítica se ha desarrollado la geopolítica crítica.
} 


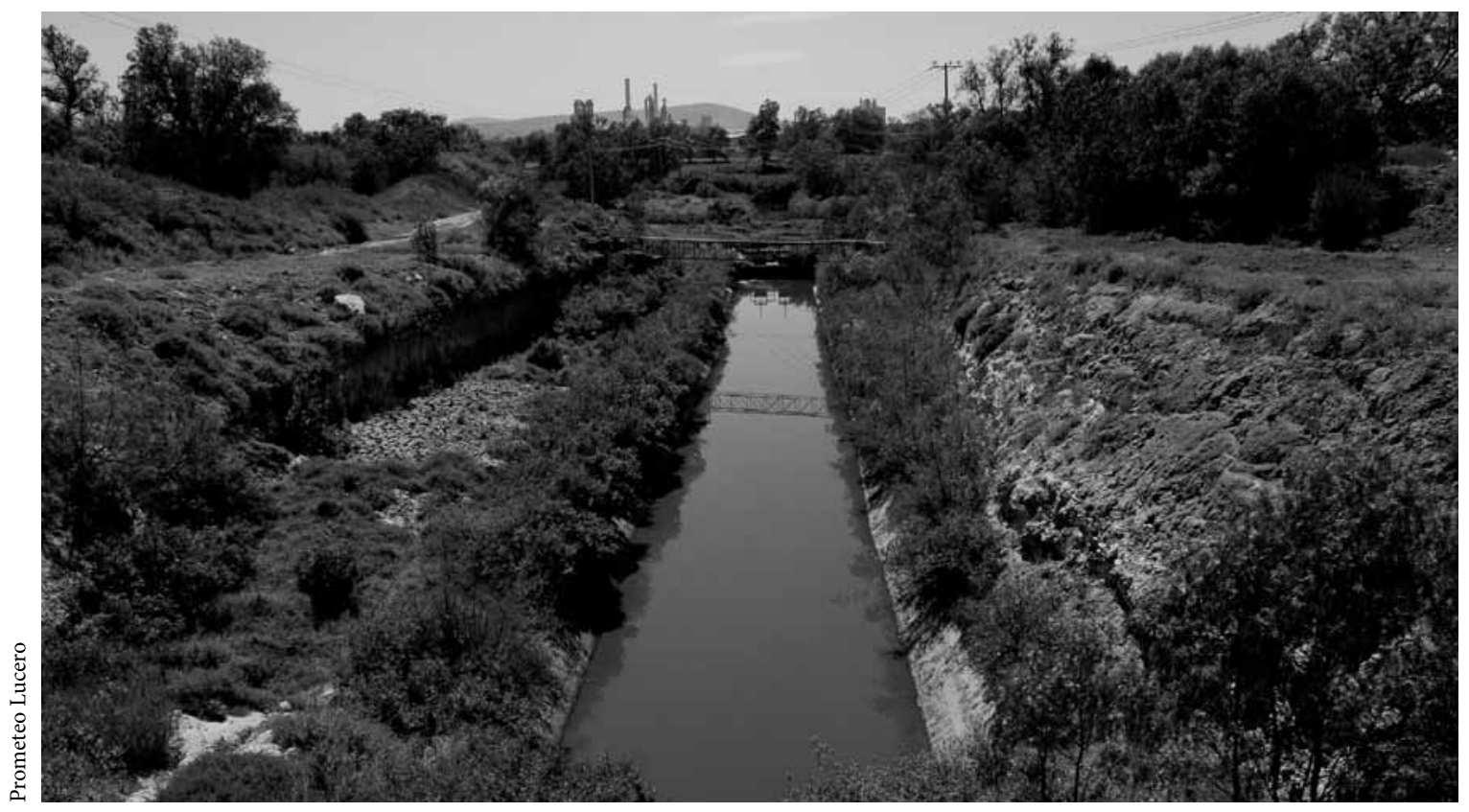

En el río Salado, Hidalgo, se vierten los desechos tóxicos provenientes del Distrito Federal, 2010.

en las décadas de 1920 y 1930 del siglo xx y sus contribuciones al pensamiento del nacionalsocialismo y la confusión al identificarla como geografía política provocaron la marginación de esta última, a excepción de la escuela norteamericana, en una corriente "neutral" y objetiva de la ciencia.

\section{El espacio en la tradición positivista}

Fred Schaefer (1971), geógrafo alemán, publicó en 1953 el ensayo Excepcionalismo en geografía, en el que realizó una mordaz crítica a la supuesta excepcionalidad del método geográfico, que se sustentaba en métodos ideográficos, ${ }^{4}$ de lo único, en un contexto positivista. Esta geografía que analizaba y describía

\footnotetext{
${ }^{4}$ De acuerdo con Lobato Correa (1998), la geografía tradicional se desarrolló entre 1870 y la década de 1950. Analizaba la relación sociedad-naturaleza, y en ella predominaban los conceptos de paisaje, región natural y región, género de vida y diferenciación de áreas, todos ellos asociados a lo único, es decir, a lo ideográfico.
}

la región o el paisaje aparecía sin rigurosidad científica al no poder establecer leyes, por lo que este geógrafo, influenciado por la escuela de Viena (Unwin, 1995), propuso el concepto de espacio por considerar que contaba con atributos indispensables para el desarrollo de la geografía dentro del positivismo: el espacio cartesiano, que era cuantificable, medible, neutral, objetivo y apolítico. ${ }^{5}$ Dicho texto inició un debate en la comunidad geográfica sobre el carácter científico de la disciplina y problematizó el concepto de espacio desde los aportes de otras ciencias, básicamente desde las matemáticas y la física. Así se desarrolló la vertiente cuantitativa en la geografía, de gran auge en las décadas de los cincuenta y sesenta del siglo $\mathrm{xx}$.

\footnotetext{
${ }^{5}$ Esta geografía, denominada genéricamente cuantitativa, presentó puntos de confluencia con el urbanismo de la Carta de Atenas (Lefebvre, 1969) y su máximo exponente, Le Corbusier ya que ambas propuestas usaban metodología cuantitativa y tenían por objetivo la planeación bajo supuestos racionalistas y funcionalistas.
} 
Una de esas discusiones del espacio dentro de la geografía cuantitativa siguió la problematización de la relatividad del espacio (Abler, 1972), una vertiente que también se nutrió de las lecturas de la Escuela de Frankfurt y con ello contribuyó al desarrollo del concepto de espacio como producción social. Por su parte, el filósofo Henri Lefebvre (1969, 1971, 1974, 1976) criticó los supuestos del espacio cartesiano y coincidió con las observaciones que realizaban las corrientes humanista, feminista y radical ${ }^{6}$ a la geografía cuantitativa y sus postulados de espacio abstracto.

\section{El espacio desde la geografía crítica}

El espacio como producción social fue definido por Henri Lefebvre, en oposición a la producción del espacio instrumental, basado en la racionalidad cartesiana de la ingeniería, de la arquitectura, del ordenamiento territorial y de la planeación. De acuerdo con el filósofo, el espacio es una totalidad, el locus de la producción y la reproducción social. No es neutral, sino político, cultural, económico, signo y significado. El espacio manifiesta los sistemas de dominación: por tanto, el capitalismo y el patriarcado. Además, la tecnología juega un rol fundamental en esta producción social. ${ }^{7}$ David Harvey, formado en Cambrigde, dio a

\footnotetext{
${ }^{6}$ Seguiremos los cuestionamientos de la geografía radical sin negar que las corrientes feministas y humanistas realizaron aportaciones a una conceptualización del espacio como producción social. Es pertinente aclarar que la denominada geografía radical de la década de 1970 se encuentra dentro de la geografía crítica, que también incorpora la feminista, la posmoderna, la posestructuralista y la humanista.

7 "Es el espacio y por el espacio donde se produce la reproducción de las relaciones de producción capitalista. El espacio deviene cada vez más un espacio instrumental. La elaboración de todo esto es consecuencia de una clase social que yo conozco muy bien; los tecnócratas. Los tecnócratas han aprendido y aprenden a servirse del espacio instrumental, en particular 'mis queridos amigos' los tecnócratas franceses. El espacio social deviene un espacio abstracto. Este espacio tiene varias propiedades bien definidas, especialmente la de ser el espacio de la propiedad. Estas propiedades - que son particulares, en tanto que espacio- consisten en ser óptico y ser visual. No es un espacio sensorial que
}

conocer su segundo libro Urbanismo y desigualdad social después de su etapa de geógrafo cuantitativo, en el que planteaba los puntos de confluencia entre él y Lefebvre. ${ }^{8}$ Ambos inician la disertación sobre urbanismo y terminan con el espacio como producción social con base en la tradición marxista. ${ }^{9}$ Otros geógrafos anglosajones, como Edward Soja, Richard Peet y William Bunge, participaron en el debate del espacio en geografía en los años setenta del siglo $\mathrm{xx}$, lo que permitió la consolidación de la categoría del espacio dentro de la disciplina.

Posteriormente, Milton Santos (1986, 1990, 1992), siguiendo a Lefebvre, estableció que el espacio es una totalidad metodológica, integrada de cinco elementos: la población, la economía, lo jurídico-político, el desarrollo científico-técnico y la segunda naturaleza, variables interrelacionadas de manera multicausal (Santos, 1986). Estos autores coinciden en que la geografía debe trabajar el concepto de espacio como producción y reproducción social. El espacio es parte de lo social, no se encuentra fuera de la sociedad, y por tanto no forma una dualidad - sociedad y espacio- $-\mathrm{y}$ tampoco una sociedad en el

interesa al conjunto del cuerpo; es un espacio óptico, que entraña problemas de signos, de imágenes, que se dirige únicamente a los ojos. Con relación al cuerpo físico es un espacio metafórico, añadiéndole una propiedad interesante, la de ser fálico.

"Esta consecuencia surge de la planificación. El espacio es cuantitativo, geométrico, matemático. Es en este espacio donde se opera la reproducción de las relaciones de producción. Reproduce los elementos anteriores, es esencialmente repetitivo y lo que repite a través de todos esos elementos es la reproducción de las relaciones de producción capitalista. Pero esa reproducción a través del espacio es cada vez más incierta, porque este espacio está en sí mismo lleno de contradicciones; hay contradicciones del espacio y es por lo que digo entre paréntesis y, a propósito, que la reproducción de las relaciones sociales de producción, asegurada por el espacio y en el espacio, implica a pesar de todo un uso perpetuo de la violencia. Espacio abstracto y violencia van juntos" (Lefebvre, 1974: 224).

${ }^{8}$ Véanse los puntos de convergencia y de divergencia entre Harvey y Lefebvre en las conclusiones de Urbanismo y desigualdad social (Harvey, 1977: 318-330).

${ }^{9}$ En la primera fase del debate se ubican dentro de la geografía radical. Posteriormente Edward Soja se posicionó en el posmodernismo y Richard Peet en el posestructuralismo. William Bunge abandonó la geografía y es taxista en Canadá. 
espacio. ${ }^{10}$ El espacio es constitutivo de lo social, por ello manifiesta a la sociedad, no la refleja (Smith, 1984). ${ }^{11}$ En consecuencia, el espacio es histórico, dinámico y político. Se abandonan así las lecturas apolíticas de la geografía y se desarrollan la geografía radical, la feminista y la humanista.

La denominada geografía radical recuperó los conceptos de espacio, escala y región de la tradición cuantitativa y los replanteó dentro de la tradición marxista. Uno de los conceptos que desarrolló y que ha sido de gran importancia para esta corriente teórica es el de segunda naturaleza, como se verá más adelante. A partir de postulados como éstos, el espacio como producción social es entendido por la geografía crítica como un concepto que permite analizar las relaciones de poder, en un sentido amplio, económico, político y de género, entre otros. Es una totalidad dinámica e inacabada. Ello explica asimismo el desarrollo vertiginoso de la geografía política y de la geografía feminista a partir de los años setenta del siglo xx. Éstas se alejaron entonces del espacio en su sentido cartesiano. Las dos principales tradiciones de espacio se contraponen teórica y políticamente. Primero, la cartesiana: el espacio puro, de la planeación que pretende el orden de lo social, que es técnica, "alejada" del caos, del poder, pertenece a la cultura hegemónica, al discurso dominante. El espacio que se encuentra envuelto en un racionamiento técnico es el que hace uso del poder y siempre pretende imponer. Por otro lado está el espacio en tanto que totalidad: producción social, integrado por todos los elementos de lo social, y por ende político. En este

\footnotetext{
${ }^{10} \mathrm{El}$ concepto de producción del espacio desarrolla un concepto muy conocido, clásico reiterativo: el de producción, pero indica un cambio en la producción, en las fuerzas productivas: pasa de la producción en el espacio a la producción del espacio (Lefebvre, 1974: 219).

${ }^{11}$ La noción de que el espacio y la sociedad "interactúan" o que los patrones espaciales "reflejan" la estructura social es no sólo burda y mecánica en su construcción, también impide profundizar las ideas respecto del espacio geográfico. Esto se debe en el fondo a que la imagen de la relación entre el espacio y la sociedad permanece unida a la concepción absoluta del espacio (Smith, 1984: 73).
}

sentido, la producción espacial implica un ejercicio de poder, el espacio producido es la realización de una intencionalidad, siempre en tensión, nunca acabado de una vez y para siempre.

El espacio, en tanto que realizado, no sólo proyectado y no siempre como se proyectó, es el resultado de los posicionamientos políticos de los actores involucrados. Por un lado están quienes detentan el poder y pretenden regular, constituir, definir, delimitar y nombrar al espacio, pero también, y es el caso que nos ocupa, éste es el de los opositores al poder, que resisten, se oponen o bien negocian elementos concretos de la producción de ese espacio. En esta relación - siempre en tensión- el poder pretende su permanencia a través del espacio, de su reconstrucción constante, no en un sentido metafórico, sino real. Paradójicamente, demanda su transformación con frecuencia, proceso en el que va el sentido de su poder. Harvey define el capitalismo como una creatividad destructiva, que nos muestra la necesidad de producción espacial, como lo sustentó Lefebvre (1974). Bajo esta lógica cobra importancia uno de los elementos del espacio y se evidencia con mayor claridad esa producción espacial, la naturaleza, convertida en segunda naturaleza. ${ }^{12}$ Milton Santos en Espacio y método plantea:

La primera naturaleza, como sinónimo de "mundo natural", sólo existió hasta el momento inmediatamente anterior en el que el hombre se transformó en ser social, a través de la producción social. A partir de ese momento, todo lo que consideremos como primera naturaleza fue transformado. Ese proceso de transformación, continuo y progresivo, constituye un cambio cualitativo fundamental de nuestro tiempo. Y en la medida que el trabajo humano tiene como base la ciencia y la técnica, se transformó por ello en tecnología históricamente acumulada (Santos, 1986: 12).

La naturaleza es el insumo material fundamental para las producciones y reproducciones sociales,

\footnotetext{
12 Para conocer más acerca de este debate dentro de la geografía véanse Smith (1984), Santos (1992) y Castree (2005).
} 
tanto materiales como simbólicas. Aquí se tratará el espacio político en tanto que totalidad, metodología que manifiesta el poder de un actor social -clase, género, grupo- capaz de producirse y reproducirse, y en ese acto generar espacio, a pesar de la oposición de otros actores sociales, de la misma escala o de otra. Recuperar el concepto de espacio como una totalidad, resultado de la producción y reproducción integrado por cinco elementos (Santos, 1986), permite establecer las variables que conforman esta totalidad compleja como un primer paso metodológico en el tratamiento de los movimientos sociales por megaproyectos.

Desagregar los elementos que integran la esfera jurídico-política del espacio mexicano hará posible la identificación de los actores, las leyes y los intereses de las tres escalas - local, estatal y federal—, sin olvidar que operan de manera simultánea y compleja. Es una segunda instancia metodológica indispensable. Analizar el proceso de producción espacial, es decir, cómo los actores políticos, la normatividad, la cultura política, las estructuras de poder, así como los elementos históricos y coyunturales contribuyen a la realización del espacio en cuestión, es el paso fundamental de esta propuesta. En este tránsito es susceptible determinar las contradicciones y paradojas, así como las tensiones y los conflictos que conlleva la realización de un espacio. Las inconformidades, los desacuerdos o las desconfianzas de los afectados están siempre presentes, aunque no de manera manifiesta, pero pueden mostrarse ante la intencionalidad de una nueva producción espacial a partir de la existente.

\section{LOS MOVIMIENTOS SOCIALES}

Aquí aparecen los movimientos sociales, tema central en las ciencias sociales. A continuación se esbozan las corrientes más significativas:

- Frustración-agresión. Fue uno de los primeros paradigmas de los movimientos sociales, predominó durante 100 años. De acuerdo con Valenzuela (1998: 181), parte de la extensión y rapidez de los cambios sociales que generan frustración, incertidumbre y tensión se van acumulando hasta que estallan y encuentran una válvula de escape en las movilizaciones violentas. Este esquema se funda sobre una base psicológica como un producto indirecto de la percepción individual de desarraigo, carencia e injusticia.

- Elección racional. Este parámetro parte del supuesto de que los individuos poseen una identidad definida y en consecuencia una jerarquía de preferencias claras a partir de las que tratan de maximizar su satisfacción. Uno de sus máximos representantes es Mancur Olson (Paramio, 2005: 24). Esta propuesta rompe con la tradición anterior, en la que el comportamiento colectivo se explicaba en términos no racionales, o por lo menos alejados del racionalismo en lo que respecta a sus fines o a su utilitarismo (Paramio, 2005: 24).

- Funcionalista. Esta corriente dentro de "los movimientos sociales se considera resultado de un contexto social caracterizado por la desorganización social como consecuencia del proceso de modernización" (Laraña, 1996: 31). El mismo autor sostiene que el movimiento es una reacción al cambio social y que tiene sus raíces en las perturbaciones psicológicas y las tensiones sociales generadas por él (Laraña, 1996: 31). Entre sus exponentes se encuentra Talcott Parsons.

- Análisis de marcos. Es una perspectiva culturalista, "parte de esquemas de interpretación, que se erigen con la conjunción de experiencias individuales y culturales, contextos sociopolíticos y filosofías tomadas del exterior" (Tamayo, 2008: 5). De acuerdo con Tamayo, los máximos representantes de esta perspectiva teórica son David Snow, Robert Benford, Burke Rochford, Steven Worden y Scott Hunt, publicados entre 1986 y 1994. A decir de Tamayo, según Snow primero se analizan los marcos de acción y posteriormente se asocian con tres conceptos ligados 
al análisis cultural: esquemas, ideologías y relatos (Tamayo, 2008: 5).

En el accionalismo o teoría de la acción destacan los trabajos presentados por Alain Touraine. Es el resultado de una crítica a la sociología clásica, a la teoría de la modernización, al funcionalismo y al análisis multivariado. Revisa en "forma radical el papel que desempeñan los actores en la acción social y los convierte en el eje central de los movimientos, cambiando así el enfoque clásico que hacía descansar el movimiento social en el movimiento estructural animado por las clases sociales" (Zapata, 1992: 470). Emmanuel Wallerstein comenta que acuñó el término movimiento antisistémico en la década de 1970, porque buscaba un vocablo que pudiera englobar lo que histórica y analíticamente habían sido dos tipos de movimientos populares marcadamente distintos y rivales en muchos sentidos: los movimientos sociales y los nacionales. Los primeros de corte socialista, mientras que los segundos pretendían la conformación de Estados nacionales. Escribe que una variedad de los movimientos antisistémicos fueron los de la

New Left: verdes, feministas, ecológicos, las minorías raciales/étnicas, quienes sostenían tener una larga historia, se caracterizaron por su rechazo a los movimientos de la vieja izquierda, por su estrategia en dos etapas y por sus jerarquías internas, por las prioridades políticas a las que adscribían - la idea de que las necesidades de las mujeres, de las minorías y del medio ambiente eran secundarias y deberían ser atendidas a posteriori de la revolución- (Wallerstein, 2003).

Estos movimientos también apelan a los derechos humanos e incorporan el discurso de la sociedad civil y de los movimientos antiglobalización. Estos últimos convocan a la lucha contra los males sociales que genera el neoliberalismo, incluyen a todas las escalas y su lema es: "Otro mundo es posible". La teoría de movilización de recursos (TMR) privilegia el análisis de la organización de la movilización social. Parte de la idea de que el origen es una injusticia, pero no es suficiente para generar un movimiento, por lo que el énfasis de esta propuesta es estudiar cómo se genera el movimiento y con qué recursos lo hace, aspecto en el que se consideran tanto los recursos materiales como los no materiales.

\section{EL ESPACIO POLÍTICO}

\section{El espacio rural bajo el régimen priista, 1927-2000}

Una de las demandas del movimiento revolucionario fue el reparto de tierra. Desde 1915 se inició una reforma agraria, que se intensificó cuando se estableció en el artículo 27 de la Constitución mexicana de 1917. Las tierras fueron repartidas en el territorio nacional, en planicies, montañas, en la costa, a lo largo de cuerpos de agua, en zonas áridas o de selva. De acuerdo con este artículo, las tierras no podían ser compradas o vendidas, lo que las sacaba de la circulación del capital. El reparto de tierras no sólo respondía a una función económica, sino a la intencionalidad de legitimar a un régimen político, producto de la Revolución Mexicana. Éste fue uno de los elementos que contribuyó a la producción del espacio rural posrevolucionario.

Otra característica política del espacio rural es que los centros agrarios están integrados por un emplazamiento urbano, denominado núcleo urbano del ejido o comunidad, donde residen los habitantes, que conforman en ese lugar un cruce de caminos políticos entre las grandes estructuras de poder del régimen: el federalismo - estados y municipios-, la estructura agraria - burocracia rural- y la estructura partidista por medio de la Confederación Nacional Campesina (CNC). El ejido, además de ser un emplazamiento rural y habitacional, es también una estructura de poder que constituye el espacio político local. Su dimensión geométrica es menor al municipio - generalmente hay un comisario municipal en el núcleo agrario o una agencia municipal formada por 


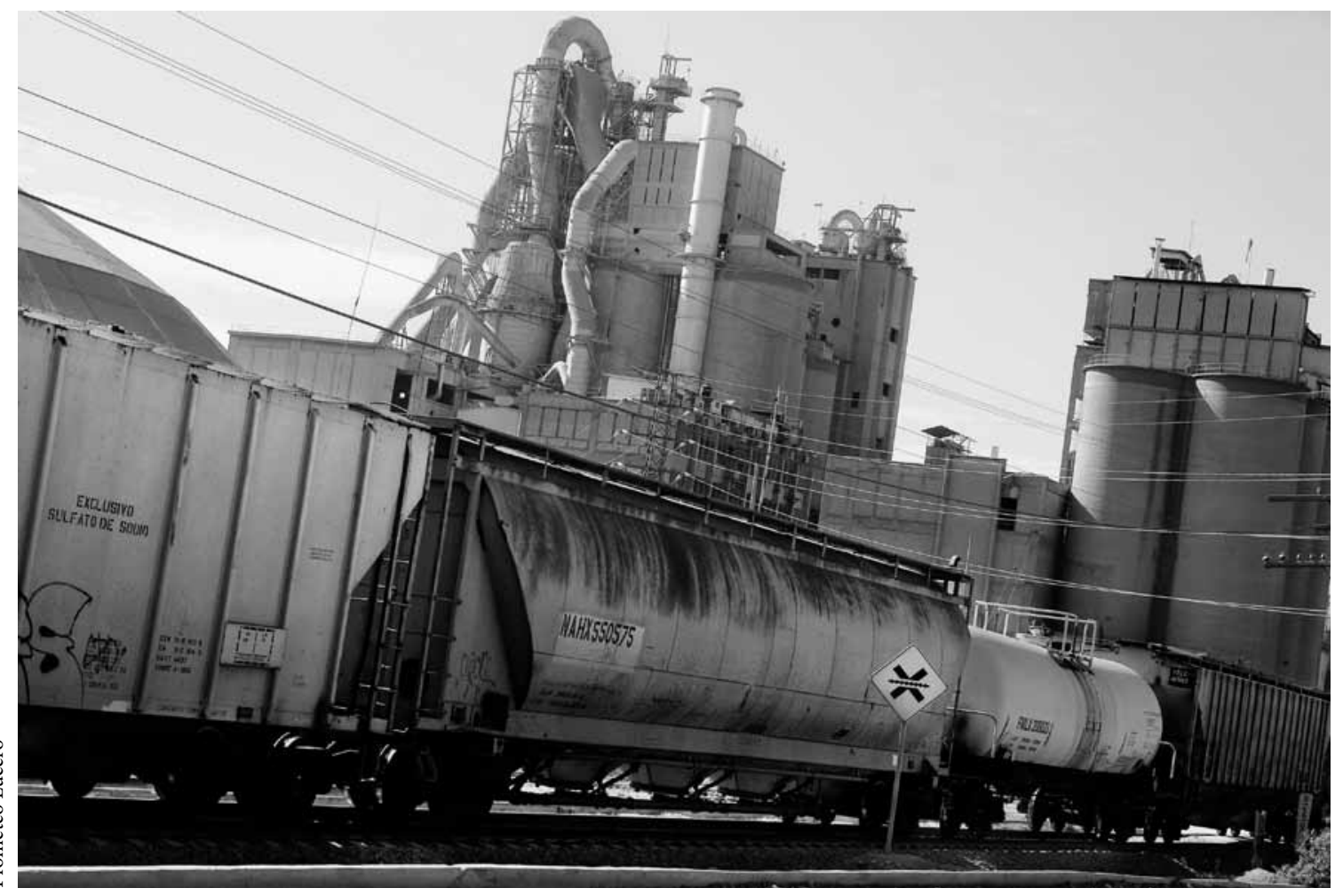

Paso del tren con desechos tóxicos, 2010.

un grupo de núcleos agrarios-. Es la menor escala local establecida por la delimitación municipal. Al mismo tiempo, de acuerdo con la estructura agraria, el máximo órgano de representación del núcleo agrario es la asamblea ejidal o comunal, que es donde se gestionan servicios y apoyos.

El campesinado, como uno de los sectores constitutivos del régimen priista, fue organizado básicamente a través de la CNC. Con ello controlaba el espacio ejidal y ejercía influencia sobre el poder municipal, al mismo tiempo que las estructuras de poder municipal, sectorial y partidista constituyeron un espacio autoritario en la escala local, en el que se podía ejercer un poder específico sobre las personas, sus necesidades y sus acciones. Podríamos decir que era un poder en un nivel de detalle muy fino, que controlaba a las personas en su vida cotidiana, en sus necesidades más apremiantes y facilitaba un ejercicio de poder "consensual". En este contexto predominaba la figura del cacique que ejerce el poder, no necesariamente de manera coercitiva, lo que contribuyó a calificar al régimen mexicano como "democrático".13

Dentro de un proyecto rural, este entramado jurídico-espacial brindaba elementos para alcanzar el objetivo planteado. Sin embargo, al cambiar el modelo de desarrollo de rural a urbano-industrial, se demandaban insumos como tierra y agua, pero según el tipo específico de lo urbano las demandas de insumos eran particulares. Por ejemplo, para el desarrollo de espacios turísticos, las playas se volvieron estratégicas, ${ }^{14}$ en tanto que para la industria papelera los

\footnotetext{
${ }^{13}$ Máxime en un contexto regional latinoamericano en el que la inestabilidad y los golpes militares eran una constante. México se presentaba como institucional y democrático.

${ }^{14}$ Es pertinente establecer que lo estratégico no es dado de manera esencial, es también una producción social acorde con el desarrollo de las fuerzas productivas y la cultura hegemónica.
} 
bosques fueron el insumo fundamental. Acapulco es el ejemplo del primer centro de desarrollo turístico bajo la lógica del capitalismo posrevolucionario:

La transformación de Acapulco se inicia en 1928, cuando el ayuntamiento obsequia a los vecinos más "distinguidos" los terrenos del antiguo ejido colonial. En 1932, el gobierno estatal del general Castrejón expropia todos los terrenos del litoral de la bahía denominada Las Huertas... Los terrenos que ocupa este último fueron vendidos por el gobierno al precio irrisorio de tres pesos el metro cuadrado al entonces secretario de Comunicaciones, Juan Andrew Almazán, quien en sociedad con el presidente de la república de ese tiempo, ingeniero Pascual Ortiz Rubio, integraron la poderosa Compañía Impulsora de Acapulco (Gómezjara, 1979: 188).

Este pasaje del sociólogo Francisco Gómezjara muestra elementos que se han repetido de manera constante en los siglos xx y xxI en México. Producciones espaciales ejecutadas bajo un discurso de desarrollo nacional, inducidas desde el Estado, dirigidas por políticos del mayor nivel que fungen como especuladores de tierra, empresarios de la construcción o inmobiliarios. Miguel Alemán Valdés, Carlos Hank González o Diego Fernández de Cevallos encarnan a este tipo de políticos. ${ }^{15}$ Los complejos urbanos -industriales, habitacionales, de infraestructura: presas, carreteras, puertos, aeropuertos, tendidos eléctricosrequerían, como se ha dicho, de tierras, agua, playas, vistas de naturaleza, lo que generalmente se encontraba bajo el usufructo de ejidatarios o comuneros, resultado de la reforma agraria. Era necesario realizar una transferencia de estos elementos bajo el usufructo de los ejidatarios o comuneros que debían ser otorgados a la propiedad privada para su incorporaciónproducción de espacio urbano. La técnica jurídica estableció un mecanismo que consistía en la expropiación de tierras por causas de utilidad pública. ${ }^{16}$

\footnotetext{
${ }^{15}$ Para profundizar sobre estos políticos empresarios véanse Gómezjara (1974) e Ibarra (2004).

${ }^{16}$ También existió la permuta, pero fue una figura jurídica menos frecuente para transferir tierras.
}

Políticamente, la estructura espacial priista, por medio de la CNC, operaba para facilitar dicha transferencia por métodos coercitivos o consensuales. Por supuesto, había inconformidades, desacuerdos y contradicciones, pero eran o trataban de ser controlados rápidamente, a partir de los mecanismos del régimen a través de sus diferentes estructuras, municipales, ejidales o priistas.

\section{La producción del espacio a través de megaproyectos}

Los megaproyectos son un tipo de espacio. Siempre han existido en tanto que producción social, están relacionados directamente con el poder, se realizan con base en el desarrollo científico-técnico, se invierten grandes cantidades de recursos económicos en su ejecución, se movilizan grandes contingentes humanos - por la demanda de mano de obra para la construcción o bien por los desplazamientos poblacionales- ${ }^{17}$ y cumplen una función simbólica de poder, desarrollo y fortaleza. En el México posrevolucionario y hasta finales del siglo $\mathrm{xx}$ podemos identificar como megaproyectos a los espacios industriales, urbanos, turísticos, a las hidroeléctricas, los trasvases, los proyectos carreteros, portuarios, entre otros (véase cuadro 1). Se han identificado algunos elementos: los insumos espaciales estaban bajo el usufructo de núcleos agrarios - ejidos o comunidades resultado de la reforma agraria-, el desarrollo del capitalismo en su fase urbano-industrial requería un uso diferente de la naturaleza, el Estado mexicano por medio de las instituciones estableció los mecanismos jurídicos necesarios para transformar el uso y usufructo de la naturaleza, la estructura de poder partidista priista operó mediante la CNC para facilitar la transferencia de la naturaleza y controló las inconformidades, el discurso usado por el gobierno mexicano fue el del desarrollo, la alta burocracia participó en las

\footnotetext{
${ }^{17}$ El tema podría desarrollarse ampliamente. Aquí sólo recuperaremos el siglo xx para México.
} 
Cuadro 1. Espacios producidos por megaproyectos

\begin{tabular}{|c|c|c|c|c|}
\hline Año & $\begin{array}{l}\text { Megaproyecto/ } \\
\text { Tipo de espacio }\end{array}$ & Espacio transformado & $\begin{array}{l}\text { Segunda } \\
\text { naturaleza }\end{array}$ & Actuación política \\
\hline 1929 & $\begin{array}{l}\text { Acapulco } \\
\text { Turístico }\end{array}$ & $\begin{array}{l}\text { Acapulco, } \\
\text { Guerrero }\end{array}$ & $\begin{array}{l}\text { Tierra con } \\
\text { playa }\end{array}$ & $\begin{array}{l}\text { Expropiación, resistencia de los } \\
\text { ejidatarios. Tensión política. }\end{array}$ \\
\hline 1946 & $\begin{array}{l}\text { Sistema } \\
\text { Hidroeléctrico } \\
\text { Ixtapatongo } \\
\text { Equipamiento }\end{array}$ & $\begin{array}{l}\text { Donato Guerra, Santo } \\
\text { Tomás de los Plátanos, } \\
\text { Valle de Bravo, Villa } \\
\text { Victoria, Villa de Allende, } \\
\text { Amanalco y Temascaltepec, } \\
\text { Estado de México }\end{array}$ & $\begin{array}{l}\text { Tierra, agua } \\
\text { superficial }\end{array}$ & $\begin{array}{l}\text { Expropiación, esperanza en que } \\
\text { recibirían beneficios del } \\
\text { desarrollo industrial. Pago } 40 \\
\text { años después. }\end{array}$ \\
\hline 1946 & $\begin{array}{l}\text { Primera fase del } \\
\text { Lerma } \\
\text { Equipamiento }\end{array}$ & $\begin{array}{l}\text { Almoloya del Río, } \\
\text { San Mateo Tezcalyacac, } \\
\text { Santa Cruz Atizapán, } \\
\text { Estado de México }\end{array}$ & $\begin{array}{l}\text { Agua } \\
\text { superficial }\end{array}$ & $\begin{array}{l}\text { Los ejidatarios recibieron a } \\
\text { cambio aula de preescolar y } \\
\text { primaria, lavaderos para mujeres } \\
\text { y exención en el pago del agua. }\end{array}$ \\
\hline 1947 & $\begin{array}{l}\text { Alce Blanco } \\
\text { Industrial }\end{array}$ & $\begin{array}{l}\text { Naucalpan, } \\
\text { Estado de México }\end{array}$ & Tierra & $\begin{array}{l}\text { Expropiación a ejidatarios y } \\
\text { permutas de sus tierras a } \\
\text { Veracruz y Texcoco. }\end{array}$ \\
\hline 1957 & $\begin{array}{l}\text { Ciudad Satélite } \\
\text { Habitacional } \\
\text { Residencial }\end{array}$ & $\begin{array}{l}\text { Naucalpan, } \\
\text { Estado de México }\end{array}$ & Tierra & $\begin{array}{l}\text { Expropiación a ejidatarios y } \\
\text { permutas a Veracruz. Miguel } \\
\text { Alemán Valdés desarrolló el } \\
\text { fraccionamiento residencial. }\end{array}$ \\
\hline 1964 & $\begin{array}{l}\text { Segunda fase del } \\
\text { Lerma } \\
\text { Equipamiento }\end{array}$ & $\begin{array}{l}\text { Ixtlahuaca } \\
\text { Jocotitlán, } \\
\text { Estado de México }\end{array}$ & $\begin{array}{l}\text { Agua } \\
\text { profunda y } \\
\text { manantiales }\end{array}$ & $\begin{array}{l}\text { La Cámara de Diputados local } \\
\text { aprobó por unanimidad la } \\
\text { extracción y trasvase del agua. }\end{array}$ \\
\hline 1972 & $\begin{array}{l}\text { Siderúrgica Las } \\
\text { Truchas }\end{array}$ & $\begin{array}{l}\text { Lázaro Cárdenas, } \\
\text { Michoacán }\end{array}$ & $\begin{array}{l}\text { Tierra con } \\
\text { salida al } \\
\text { mar }\end{array}$ & $\begin{array}{l}\text { Expropiación de tierras ejidales, } \\
\text { los campesinos se integraron a la } \\
\text { construcción del puerto y } \\
\text { posteriormente al sindicato } \\
\text { minero. }\end{array}$ \\
\hline 1976 & $\begin{array}{l}\text { Tercera fase del } \\
\text { Lerma* }^{*} \\
\text { Equipamiento }\end{array}$ & $\begin{array}{l}\text { Reconversión del Sistema } \\
\text { Ixtapatongo al Sistema } \\
\text { Lerma y construcción de la } \\
\text { Planta Potabilizadora de } \\
\text { Berros }\end{array}$ & $\begin{array}{l}\text { Agua y } \\
\text { tierra }\end{array}$ & $\begin{array}{l}\text { Expropiación para la } \\
\text { construcción de la Planta } \\
\text { Potabilizadora de Berros. Sin } \\
\text { conflicto, a pesar de no haber } \\
\text { cumplido con lo pactado. }\end{array}$ \\
\hline 1976 & $\begin{array}{l}\text { Cancún } \\
\text { Turístico }\end{array}$ & Isla Mujeres y Cozumel** & $\begin{array}{l}\text { Tierra, } \\
\text { playa, } \\
\text { cenotes }\end{array}$ & $\begin{array}{l}\text { Negociación con el cacique de la } \\
\text { región Nassin Joaquín (padre de } \\
\text { Pedro Joaquín Codwell). }\end{array}$ \\
\hline
\end{tabular}

* Esta fase es la reconversión del Sistema Hidroeléctrico Ixtapatongo en la tercera fase del Sistema Lerma al conectar el ducto que abastece de agua al Estado de México en la cuenca del Lerma y a la cuenca de la ciudad de México.

** De ambos municipios se constituyó el municipio de Benito Juárez, que no existía.

Fuente: Elaboración propia con base en Gómezjara (1974, 1979), Restrepo (1984), Cirelli (1997), Rodríguez (2009) e Ibarra (2007). 
producciones espaciales en calidad de parte empresarial, el desarrollo científico-técnico se hizo presente y realizó profundos cambios a partir de magnas construcciones, que favorecieron al gremio de la ingeniería y a la industria de la construcción — del tabique en la década de 1950, del cemento y del acero-. El elemento concomitante de todas estas producciones espaciales son las poblaciones afectadas, desplazadas, despojadas, "invisibles", con gran frecuencia sin movimientos sociales, lo que no implica aceptación, acuerdo o indiferencia.

Este último es un punto clave. Una diversidad de estudios -Gómezjara (1974), Restrepo (1984), Barabas (1990, 1992), Bartolomé (1992), Scott (1989, 1992), Cirelli (1997) - indica la presencia de desacuerdo, molestia y frustración, o esperanza por el contrario. Es evidente la falta de organización o la incapacidad para boicotear los megaproyectos, es decir los espacios hegemónicos. En consecuencia, consideramos que la producción de espacios hegemónicos después de la Revolución Mexicana se realizó bajo la directriz del Estado mexicano, contando con una aparente legitimidad entre ejidatarios o comuneros usufructuarios de los insumos fundamentales para la producción del espacio urbano, a pesar de la existencia de las inconformidades y desacuerdos que no alcanzaron para frenar estas construcciones. La presencia de grupos inconformes con estas producciones espaciales pueden localizarse en la prensa local y estatal, si bien son pocos los estudios que dan cuenta de ello. Sin embargo, estas inconformidades y descontentos han formado parte del espacio y serán de la mayor importancia tiempo después, en el desarrollo de los movimientos sociales en contra de los proyectos espaciales, tanto privados como estatales.

\section{LOS MOVIMIENTOS SOCIALES POR MEGAPROYECTOS}

Para el caso de los movimientos rurales, Blanca $\mathrm{Ru}-$ bio (2007), estudiosa del campo mexicano, precisa que en las décadas de los sesenta y setenta del siglo Xx los movimientos rurales se incrementaron debido a las condiciones generales de luchas sociales, influenciadas, por ejemplo, por la Revolución Cubana, por lo que los denomina movimientos ofensivos. Asegura que a partir de la década de 1980 se observa una disminución de los movimientos en el campo. En México se pasó de una fase ofensiva a una defensiva. ${ }^{18} \mathrm{Si}$ bien es cierto que México no registró movimientos sociales a la ofensiva ${ }^{19}$ bajo esta lectura económica, sí había procesos políticos que cuestionaban al régimen mexicano, que junto a las crisis económicas recurrentes colocaron por primera vez al gobierno priista en una encrucijada social y política. En las elecciones de 1988, el debilitamiento del Partido Revolucionario Institucional (PRI) se hizo patente, aunque no fue sino hasta el proceso electoral de 2000 que perdió la presidencia por primera vez en 73 años, frente al triunfo del Partido Acción Nacional (PAN). En ese contexto se desarrollaron los movimientos de Tetelcingo, Tepoztlán, Atenco y La Parota. Sostengo que estos movimientos muestran una transformación política de la sociedad mexicana y una forma diferente de relación entre la sociedad y el Estado mexicano, lo que se evidencia en la intención de producción del espacio hegemónico.

Los megaproyectos fueron visualizados por las ciencias sociales en México en épocas relativamente recientes - años setenta del siglo $\mathrm{xx}$ - . Destacan las investigaciones realizadas por los antropólogos básicamente - Bartolomé y Barabas (1990), Barabas y Bartolomé (1992), Bartolomé (1992), Robinson $(1989,1992)$ - , que analizaron los impactos por desplazamientos ante las construcciones de las presas hidroeléctricas Miguel Alemán en Veracruz y Cerro de Oro. Restrepo, por su parte, se ocupó en 1984 del caso de la Siderúrgica Lázaro Cárdenas.

\footnotetext{
${ }^{18}$ A excepción del movimiento del Ejército Zapatista de Liberación Nacional (EZLN), que representó un movimiento a la ofensiva, pero que ha disminuido de manera significativa, el cual no será analizado en este trabajo ya que se originó como un movimiento revolucionario más que como un movimiento social, siguiendo las conceptualizaciones de Lopes de Souza.

${ }^{19}$ A diferencia de Brasil, que se ha caracterizado por un periodo a la ofensiva, representado por el movimiento Sin Tierra.
} 


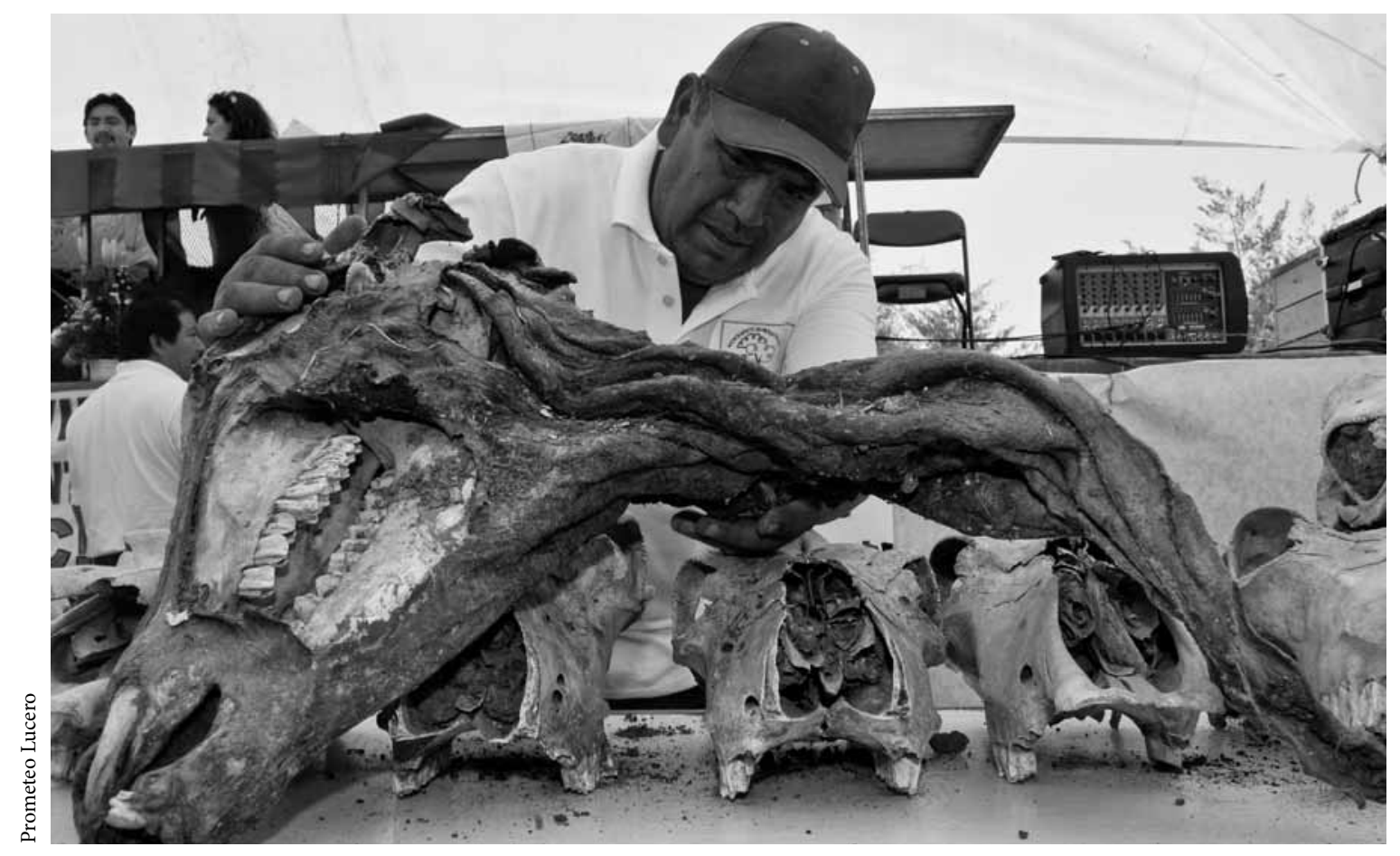

Un habitante de la franja contaminada de Apaxco-Atotonilco, Estado de México, muestra a medios de comunicación uno de los restos de ganado que murió al beber agua contaminada del río, 2010.

Los trabajos elaborados desde la antropología - que se ocupa del espacio simbólico- pusieron énfasis en las relaciones establecidas entre los ingenieros -que manejan el espacio cartesiano-, como actores sociales y los habitantes de las zonas de inundación y desplazamiento, casi siempre indígenas. Las investigaciones posteriores de la biología y la sociología se centraron en los impactos ecológicos de los megaproyectos y establecieron un eslabonamiento con los nuevos movimientos sociales, que se han definido como ambientalistas, indigenistas o de derechos humanos: por ejemplo, Tetelcingo -Celestino (2004)—, Tepoztlán —Rosas (1997), Velázquez García (2004, 2008) - y Atenco - Alcayaga (2002), Velázquez García (2004)—.

El movimiento de San Juan Tetelcingo fue desarrollado por los pueblos nahuas del Alto Balsas en Guerrero ante un proyecto que contemplaba la afectación de 14000 hectáreas. Esta primera mo- vilización se generó bajo un discurso que bordaba entre lo identitario y lo ambiental. Por un lado se encontraba la Comisión Federal de Electricidad (CFE) y por otro las comunidades de 30 núcleos agrarios y de siete municipios: Tepecoacuilco, Copalillo, Mártir de Cuilapan [Apango], Zumpango de Eduardo Neri, Atenango del Río, Huitzuco y Zitlala, con una población de más de 30000 habitantes. El 21 de octubre de 1990 se constituyó el Consejo de Pueblos Nahuas del Alto Balsas en contra del Proyecto Hidroeléctrico San Juan Tetelcingo (PHSJT), cuyo movimiento se posicionó como una movilización identitaria (Celestino, 2004). El estado de Guerrero presenta una historia de movimientos campesinos, magisteriales y de clase. Existen antecedentes de construcciones de megaproyectos: la Presa Rubén Figueroa en 1960, la Autopista del Sol y el tendido eléctrico, así como los desarrollos turísticos de Acapulco e Ixtapa, entre los más importantes, 
con expropiación de tierras e incumplimiento en el pago. Además, en la escala internacional se desarrollaba la conmemoración de los 500 años de la Conquista española. Todos los elementos contribuyeron en su organización en 1992.

Un segundo movimiento en oposición a un megaproyecto surgió en el municipio y ejido de Tepoztlán, en el estado de Morelos, en 1994, contra el proyecto de un club de golf de la empresa Kladt-Sobrino (кs). El diseño demandaba 187 hectáreas de tierra, así como agua para su construcción y mantenimiento. La inversión total sería de 478 millones de dólares (Velázquez, 2008: 75) e impactaría a 26503 personas que habitaban el municipio en 1995 según el Conteo del mismo año (INEGI, 1995). La movilización social se desarrolló bajo un claro discurso ambientalista que se transformó en un discurso identitario que incluía a las tradiciones, el pasado, el territorio y con ello sus elementos constitutivos - agua y tierras fundamentalmente-. El Comité de Unidad Tepozteca fue el actor preponderante que organizó la resistencia social contra el proyecto espacial. El movimiento de Tepoztlán se desarrolló en 1994, tres años después del de Tetelcingo, del que reciben solidaridad y enseñanzas, como lo demuestra la crónica de Rosas (1997).

Una tercera movilización social se presentó en 2001 contra el proyecto de construcción del aeropuerto alterno de la ciudad de México. Se expropiarían 5376 hectáreas y serían transferidas a la iniciativa privada. Tres municipios del Estado de México se verían transformados: San Salvador Atenco, Texcoco y Chimalhuacán. El proyecto abarcaría 13 núcleos agrarios. Ante tal futuro, los ejidatarios se opusieron a la construcción de lo que se conoció como el proyecto más ambicioso del sexenio del panista Vicente Fox (2000-2006). Este movimiento permitió identificar dos grupos antagónicos: los ejidatarios y los habitantes de San Salvador Atenco, principal pero no exclusivamente, quienes conformaron el Frente de Pueblos en Defensa de la Tierra, que confrontó al Estado mexicano, integrado por el gobierno federal del PAN, el gobierno local del Estado de México en donde se construiría el aeropuerto, y al grupo político de esta entidad federativa. ${ }^{20} \mathrm{El}$ caso de Atenco fue una clara muestra de la acumulación de un saber actuar frente al Estado mexicano. Los antecedentes en San Juan Tetelcingo y Tepoztlán, donde además de las movilizaciones se habían interpuesto acciones jurídicas ante la Suprema Corte de Justicia, un discurso de justicia, así como uno "ecológico", le otorgaron a este movimiento el respaldo de una buena parte de la opinión pública. ${ }^{21}$ Esta movilización se tornó altamente combativa y logró frenar dicho proyecto.

Lo que observamos es un mayor margen de autonomía de la asamblea ejidal, que durante décadas fungió como la estructura de control de los campesinos. Esa misma institución fue usada para revertir la embestida de los grupos hegemónicos en la producción del espacio. La construcción de megaproyectos representa amplias ganancias para el capitalismo, ya sea en su modelo de sustitución de importaciones o en su vertiente neoliberal. A este último le permite la inserción del capital a recursos de los que estaba vetado - tierra y agua-, además de una realización más rápida del capital, por medio de las infraestructuras - carretera, ferroviaria o portuaria-. Simultáneamente, se fortalecerían los grupos de poder político y económico más importantes del país. En el caso de Atenco saldría beneficiado el grupo priista del Estado de México: el Grupo Atlacomulco, mientras que para el PAN y el entonces presidente Vicente Fox el megaproyecto del aeropuerto alterno de la ciudad de México cumpliría un papel simbólico como la máxima obra del sexenio de la transición.

El cuarto movimiento fue la respuesta organizada de 19 ejidos y comunidades de cuatro municipios del estado de Guerrero - Acapulco, Juan R. Escudero, San Marcos y Chilpancingo-, en 2003, contra la Hidroeléctrica La Parota. Este proyecto demandaba

\footnotetext{
${ }^{20}$ El Estado de México tiene un grupo priista de gran fuerza política constituido desde 1945 bajo la dirección de Isidro Fabela: el Grupo Atlacomulco, que ha operado para mantener posiciones hegemónicas dentro del Partido Revolucionario Institucional, pero también ha jugado un papel fundamental en la construcción de infraestructura dentro de la entidad mexiquense.

${ }^{21}$ Con base en el precio que estableció el gobierno mexicano antes de las expropiaciones: se pagarían .80 de dólar por metro cuadrado.
} 
14213 hectáreas que serían inundadas por la presa y afectaría a 25000 personas. Fue presentado por la CFE para brindar energía eléctrica a los estados de la costa del Pacífico. A partir de dicha oposición se constituyó el Consejo de Ejidos y Comunidades Opositores a la Presa La Parota (CECOP). La CFE planteaba construir una planta hidroeléctrica en la que nuevamente la población afectada era visualizada ajena a los derechos ciudadanos, pues colocaba a los ejidatarios y comuneros como sujetos que necesitaban información técnica y no acuerdos políticos, ${ }^{22}$ a lo que habría que sumar las experiencias de despojo e incumplimientos por afectación de proyectos anteriores. La rápida comunicación con movimientos similares en otras partes del país, principalmente con los de Atenco, Tepoztlán, Guerreros Verdes, ${ }^{23}$ hicieron posible un movimiento social que se organizó básicamente en los bienes comunales de Cacahuatepec y que contaba con el apoyo del resto de los ejidos. Con la experiencia, en su organización recurrieron a movilizaciones, marchas, declaraciones $y$, sobre todo, a la recuperación de la asamblea de los bienes comunales como una instancia de decisión política sobre sus tierras y su agua.

La resistencia a estos proyectos diseñados desde la burocracia del espacio cartesiano encontró oposición de la población que se vería afectada por el objetivo de construir, ordenar, planear o diseñar el territorio. Los derrotados por las resistencias sociales fueron los sectores de la industria de la construcción, como la del cemento, la del acero, las empresas constructoras y de diseño, además de las industrias involucradas en los servicios recreativos, comerciales, empresas inmobiliarias y demás. Los movimientos sociales descritos anteriormente coinciden en haber logrado

\footnotetext{
${ }^{22}$ En trabajo de campo realizado durante mayo de 2004 se observó que el equipo de la CFE informó a la comunidad de los aspectos técnicos del proyecto, pero nada sobre lo que a la población le interesaba: el costo del metro cuadrado en caso de expropiación y el lugar donde serían reubicados.

${ }^{23}$ Movimiento de habitantes de Acapulco en contra de la venta del Parque Papagayo para la construcción de una tienda de autoservicio en 1989. El gobernador era Ruiz Massieu y el presidente de la república, Carlos Salinas de Gortari.
}

detener megaproyectos que representaban intereses del capital neoliberal, política económica instaurada en México en 1982. Los desacuerdos por megaproyectos son cada vez más frecuentes en la esfera política. Las manifestaciones de inconformidad que involucran el sentido de la naturaleza - tierra, agua, playa, entre otras - parecen indicar una mayor preocupación por los aspectos ambientales. Sin embargo, se trata aquí del perfil de los procesos políticos en los que la población mexicana se incorpora con claro posicionamiento político respecto de las producciones espaciales que dirige el Estado mexicano - bajo los postulados del espacio cartesiano-, y que paradójicamente demandan un uso diferente de elementos que constituyen el espacio, entre los más importantes la segunda naturaleza.

Se ha registrado un mayor número de tensiones que derivan en movimientos sociales. De ello dan cuenta actores locales-regionales que han recuperado una tradición contestataria de movilizaciones por desacuerdo con las políticas que plantea el Estado mexicano por medio del gobierno. Con ello queda de manifiesto el proceso de democratización que intenta un sector de la sociedad mexicana, aunque por otro lado persiste la cultura política autoritaria del Estado capitalista neoliberal, que va más allá de los políticos priistas que la consolidaron y que se ha incorporado al nuevo gobierno mexicano encabezado por el Partido Acción Nacional. ${ }^{24}$

Los integrantes de los movimientos contra los megaproyectos aprendieron de otras experiencias que habían escuchado o vivido, expropiaciones de tierras por causas de utilidad pública, pago de indemnización con base en parámetros esencialistas, ${ }^{25}$ por tanto

\footnotetext{
${ }^{24}$ No es una casualidad que destacados burócratas de los sexenios priistas, como Luis Téllez Kuenzler, Guillermo Ortiz y Francisco Gil Díaz, hayan tenido puestos significativos con el gobierno panista o con carteras de organismos internacionales de apoyo al neoliberalismo, como José Ángel Gurría Treviño, Santiago Levy Algazi o el mismo Ernesto Zedillo Ponce de León.

${ }^{25}$ El valor del suelo se cotiza en función de su calidad para la agricultura, aunque luego el uso de suelo se transforme a urbano. Una clara muestra del razonamiento esencialista del valor del suelo, en la que sólo se concibe para la agricultura, pero que en el
} 
muy bajos si se considera que la mayoría de las tierras no poseen riego, se encuentran en zonas de pendiente abrupta, de pedregales o bien en selvas, por lo que casi ninguno es bueno para la agricultura. Además, con reubicaciones en condiciones desfavorables para su reproducción social y atraso de hasta 30 años en la indemnización. Estos movimientos se desarrollaron en el contexto del debilitamiento del régimen priista, que había perdido margen de maniobra, y el panismo no ha constituido mecanismos de operación política a una escala local como el PRI. Simultáneamente, el neoliberalismo demanda una serie de insumos respecto de los cuales la naturaleza cobra un valor diferente del que venía operando.

\section{CONCLUSIONES}

A partir de la propuesta metodológica para el análisis de los movimientos sociales por construcciones espaciales a través de los megaproyectos, para el caso mexicano identificamos, por el momento, dos periodos: el primero desde la constitución del PRI en 1929 — caso Acapulco- y el segundo en 1989, con San Juan Tetelcingo como el sitio de quiebre de esta primera forma de producir espacios. La primera fase se caracterizó por una forma de producción espacial en la que el corporativismo del PRI operó sobre la organización rural básica del campo mexicano, es decir, sobre los núcleos agrarios - ejidos y comunidadespor consenso. Cuando esta fórmula no funcionaba se utilizaba la coacción por medio de mecanismos que iban desde la cooptación hasta la violencia y la represión, lo que permitió la construcción de grandes obras de infraestructura que sustentaron el desarrollo de base urbano-industrial característico del denominado milagro mexicano. Es pertinente destacar que el establecimiento de estos espacios no niega la inconformidad y el desacuerdo que causaron por su expropiación o permuta, así como por el valor de

fondo es una forma de despojar a los ejidatarios de aquellos elementos necesarios para desarrollar los grandes megaproyectos. las indemnizaciones, el incumplimiento del pago, las reubicaciones y las transformaciones del espacio. Este desacuerdo con el gobierno y sus instituciones no desapareció, se transformó en un saber que ha estimulado una cultura política fincada en la desconfian$\mathrm{za}$, la incredulidad y la molestia con las estructuras de poder, identificadas genéricamente por la población como "el gobierno".

Los años setenta fueron una década de grandes movilizaciones en la que se ubican los nuevos movimientos sociales. La represión a la que recurrió el Estado mexicano, el desgaste del régimen político y la apertura electoral de las minorías forjaron un contexto que brindó cauces de participación a los disidentes del régimen, que coincidieron con una academia con compromiso social. Estos factores explican la irrupción de movilizaciones en campos de acción antes controlados férreamente por medio de la estructura corporativa del PRI. En la década de 1980, ante el agotamiento del modelo de sustitución de importaciones, las crisis recurrentes, los planteamientos neoliberales y la consecuente refuncionalización de la naturaleza, con el cada vez más evidente desgaste del régimen priista, y la participación de una ciudadanía que descubría que podía manifestar su desacuerdo y organizarse ante lo que consideraba injusto, se desarrolla la segunda fase de producción espacial por megaproyectos. Hablamos de la propuesta de construcción de la planta hidroeléctrica en San Juan Tetelcingo, Guerrero, que marca el inicio de una nueva etapa: de una sociedad que se organiza con el objetivo de frenar el proyecto espacial del Estado mexicano.

En ese sentido, el movimiento social que se opone a un proyecto con un uso del espacio diferente al que le asignaba la población local evidencia el atributo político del espacio. La intencionalidad de transformación, apropiación y uso de la naturaleza es un elemento sustantivo siempre entrelazado a la operación política. Es uno de los núcleos presentes en movimientos sociales ante megaproyectos. Justamente la forma en que se realiza el espacio, producto de la esfera jurídico-política, nos permite indicar el 


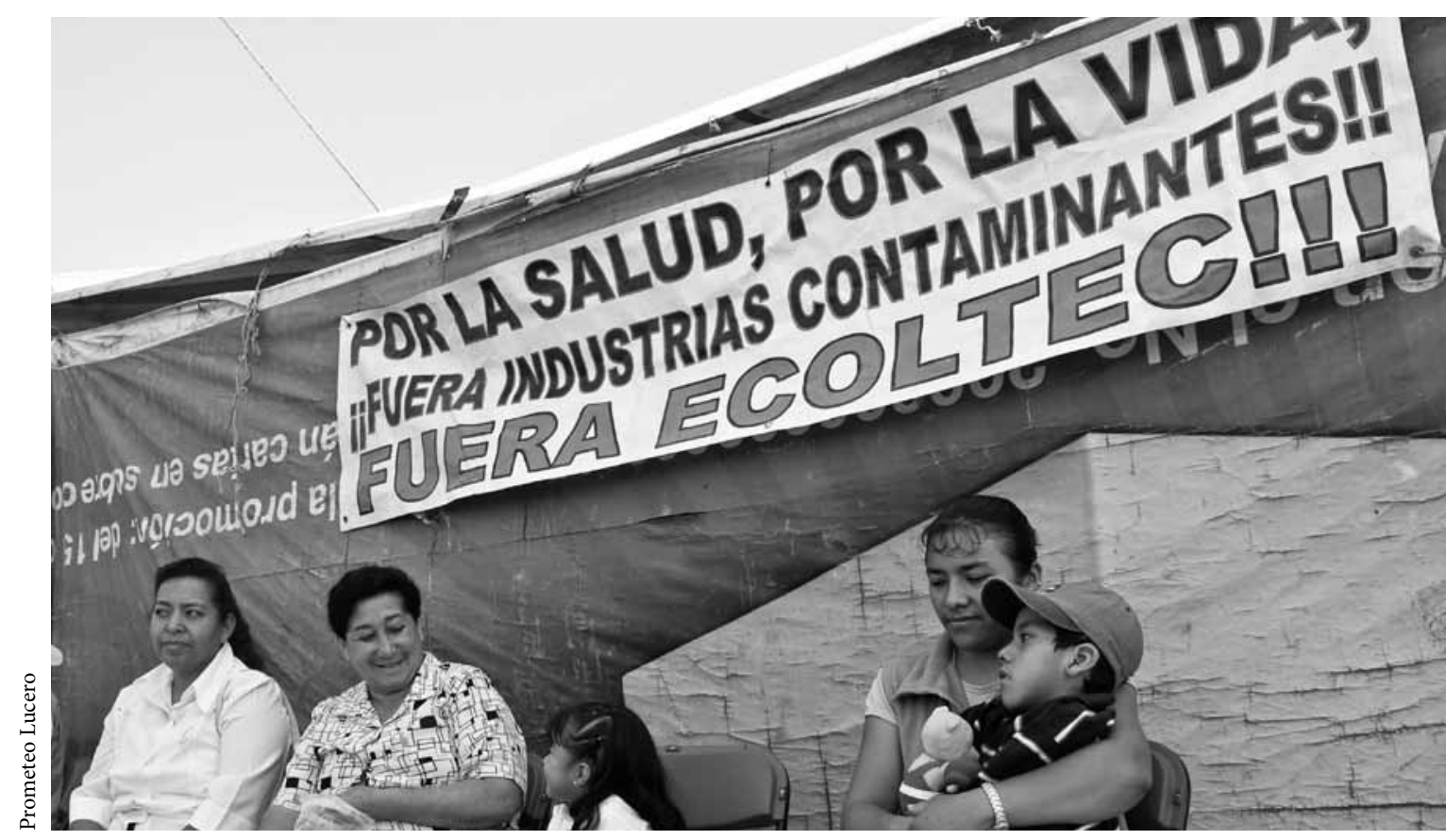

Los habitantes señalan a Ecoltec como responsable de la muerte de los once campesinos y de frecuentes incidentes, 2010.

tipo de espacio de poder: democrático, autoritario o totalitario. También muestra cuáles son espacios de consenso, de tensión y de conflicto, y nos puede indicar cómo se pasa de un espacio a otro. Partimos de la idea de que la geografía política contribuye al conocimiento de los espacios de poder regionales y locales que constituyen el espacio mexicano.

En relación con los cuatro casos señalados, se logró frenar la producción de espacios hegemónicos desde la escala local al articular resistencias a producciones espaciales que transformarían el uso de la naturaleza. Sin embargo, son movimientos a la defensiva, aún no se han logrado conformar movimientos a la ofensiva, a pesar de la crisis económica neoliberal de 2009. Dicha crisis económica está dejando su impronta en los megaproyectos y en los movimientos sociales, los primeros de los cuales serán pospuestos por problemas presupuestarios, ${ }^{26} \mathrm{lo}$

${ }^{26}$ El megaproyecto del presente sexenio es Punta Colonet: "el puerto comercial más grande del país con más de cinco mil hectáreas de terreno y que busca una inversión de, por lo menos, que les da un respiro a los acosados movimientos sociales ${ }^{27}$ bajo un régimen que no ha transitado del todo del autoritarismo a la democracia.

2 mil millones de dólares, se encuentra ubicado a unos 130 kilómetros de Ensenada y a 240 de Tijuana. Los diseñadores de este proyecto buscan que su ubicación geográfica sea uno de los puntos de mayor ventaja para convertirlo en un epicentro comercial, el cual competirá y disminuirá el tráfico que tienen actualmente los puertos de Los Ángeles y Long Beach en EU. El proyecto se prevé que sea finalizado en 2020 con una inversión adicional de mil 100 millones de dólares para la construcción de una planta de generación de electricidad y una regasificadora de gas natural. Además se pretende desarrollar una zona hotelera, una zona industrial, comercial y habitacional en el lugar. De acuerdo con el diario The Angeles Business Journal, Punta Colonet tendría una capacidad para movilizar anualmente más de seis millones de contenedores, a los cinco años de entrar en operación" (El Universal, 28 agosto de 2008).

${ }^{27}$ Para el caso de Atenco, cuatro años más tarde fueron detenidos los principales líderes del movimiento, se usó la fuerza pública federal y estatal, las mujeres fueron vejadas y los hombres golpeados. A los líderes se les impuso una condena de 123 años. Cuatro años después, la Suprema Corte de Justicia declaró que dicha condena se fincó en declaraciones infundadas por parte del Ministerio Público del Estado de México. Después de cuatro años y 27 días, Ignacio del Valle y Felipe Álvarez salieron de prisión. 


\section{Bibliografía}

Abler Ronald, John S. Adams y Peter Gould, 1972, La geografía como ciencia, Prentice Hall International, Londres.

Alcayaga, Cristina, 2002, Atenco, el peso del poder y el contrapeso de la resistencia civil, Porrúa, México.

Barabas, Alicia y Miguel Bartolomé, 1992, “Antropología y relocalizaciones", en Alteridades, año 2, núm. 4, Universidad Autónoma Metropolitana-Iztapalapa, pp. 5-15.

Bartolomé, Miguel, 1992, "Presas y relocalizaciones de indígenas en América Latina”, en Alteridades, año 2, núm. 4, Universidad Autónoma Metropolitana-Iztapalapa, pp. 17-30.

- y Alicia Barabas, 1990, La Presa Cerro de Oro y el Ingeniero el Gran Dios, t. II, Instituto Nacional Indigenista, Consejo Nacional para la Cultura y las Artes, México.

Camacho Guzmán, Damián Gustavo, 2008, "Atenco arma su historia”, tesis de maestría en desarrollo rural, División de Ciencias y Humanidades, Posgrado en Desarrollo Rural, Universidad Autónoma Metropolitana-Xochimilco.

Castree, Noel, 2005, "Socializing Nature: Theory, Practice, and Politics", en Social Nature Theory, Practice, and Politics, Blackwell, Nueva York, pp. 1-21.

Celestino Solís, Eustaquio, 2004, Botas de maíz: jerarquía de cargos y ritual agrícola en San Juan Tetelcingo, Centro de Investigaciones y Estudios Superiores en Antropología Social, México.

Cirelli, Claudia, 1997, "La transferencia de agua: el impacto en las comunidades origen del recurso. El caso de San Felipe y Santiago, Estado de México", tesis de licenciatura en antropología social, Universidad Iberoamericana, México.

Cisneros Sosa, Armando, 2006, "Movimientos sociales frente al Estado en la transición mexicana”, en Sociológica, año 21, núm. 61, pp. 71-93.

El Universal, 2008, “¿Qué es Punta Colonet?”, en El Universal en línea: <http://www.el-universal.com.mx/notas/533714.html>, consultado el 30 de junio de 2009.

Giménez, Gilberto, 1994, "Los movimientos sociales. Problemas teórico-metodológicos", en Revista Mexicana de Sociología, año 56, núm. 2, pp. 3-24.

— 2001, "Cultura, territorio y migraciones. Aproximaciones teóricas”, en Alteridades, vol. 11, núm. 22, pp. 5-14.

Gómezjara, Francisco, 1974, "Acapulco: despojo y turismo", en Problemas del desarrollo, Instituto de Investigaciones
Económicas, Universidad Nacional Autónoma de México, año 5, núm. 19, pp. 126-147.

, 1979, Bonapartismo y lucha campesina en la Costa Grande de Guerrero, Editorial Posada (Colección Ideas Políticas), México.

Harvey, David, 1977, Urbanismo y desigualdad social, Siglo XXI, Madrid.

—, 2008, "El neoliberalismo como destrucción creativa”, Instituto Argentino para el Desarrollo Económico, en línea: <http://www.iade.org.ar//modules/ noticias/print.php?storyid $=2378>$.

Ibarra García, María Verónica, 1997, "El cacicazgo urbano", tesis de maestría en geografía, Facultad de Filosofía y Letras, Universidad Nacional Autónoma de México, México.

— , 2004, "Los espacios de poder del Grupo Atlacomulco", tesis de doctorado en geografía, Facultad de Filosofía y Letras, Universidad Nacional Autónoma de México, México.

Instituto Nacional de Estadística, Geografía e Informática (INEGI), 1995, Conteo de Población y Vivienda 1995, en línea: <http://www3.inegi.org.mx/sistemas/iter/consultar_info.aspx $>$.

Laraña, Enrique, 1996, "La actualidad de los clásicos y las teorías del comportamiento colectivo", en Revista Española de Investigaciones Sociales, núm. 74, pp. 15-43.

Lefebvre, Henri, 1969, El derecho a La Ciudad, Ediciones Península (Colección Historia, Ciencia, Sociedad, núm. 44), Barcelona.

, 1971, De lo rural a lo urbano, Ediciones Península (Colección Historia, Ciencia, Sociedad, núm. 79), Barcelona.

, 1974, "La producción del espacio", en Papers. Revista de Sociología, Universidad Autónoma de Barcelona, núm. 3, pp. 219-229.

- 1976, Espacio y política. El derecho a La Ciudad II, Ediciones Península (Colección Historia, Ciencia, Sociedad, núm. 128), Barcelona.

Lobato Correa, Roberto, 1998, "Espacio, un concepto clave de la geografía”, en Graciela Uribe Ortega (comp.), Cuadernos de Geografía Brasileña, pp. 21-46.

Paramio, Ludolfo, 2005, “Teorías de la decisión racional y de la acción colectiva”, en Sociológica, El Colegio de México, año 19, núm. 57, pp. 13-34.

Restrepo, Iván, 1984, Las Truchas. ¿Inversión para la desigualdad?, Centro de Ecodesarrollo y el Océano, México.

Robinson, Scott, 1989, "Los reacomodos de poblaciones a raíz de obras hidroeléctricas e hidráulicas", en Anuario de Antropología, Universidad Autónoma Metropolitana-Iztapalapa, México, pp. 139-162. 
1992, "El proyecto hidroeléctrico Pangue, Río Bío Bío, Chile y su importancia para el futuro de las obras de infraestructura", en Alteridades. Reacomodos y construcción de presas, año 2, núm. 4, pp. 85-91.

Rodríguez, Antonio, 2009, "La producción del espacio regional durante el proceso de transferencia de agua, de la comunidad agrícola a la agroindustrial: el caso de Pasteje y los Reyes 1940-1980", tesis de maestría en estudios regionales, Instituto de Investigaciones Históricas "Dr. José María Luis Mora", México.

Rosas, María, 1997, Tepoztlán, crónica de desacatos y resistencia, Era, México.

Rubio, Blanca, 2007, "Las organizaciones independientes en México. Semblanza de las opciones campesinas ante el proyecto neoliberal", en Sistema político mexicano. Antología de lecturas, Facultad de Ciencias Políticas y Sociales-Universidad Nacional Autónoma de México, pp. 301-322.

Santos, Milton, 1986, "Espacio y método", en Geocrítica. Cuadernos críticos de geografía humana, año 12, núm. 65, Universidad de Barcelona, Barcelona. Madrid.

, 1990, Por una nueva geografía, Espasa Calpe,

_ 1992 , “1992: a redescoberta da Natureza”, en Estudos Avançados, vol. 6, núm. 14, pp. 95-106.

1584 Schaefer, Fred, 1971, Excepcionalismo en geografía, traducción y estudio introductorio de Horacio Capel, Universidad de Barcelona, Barcelona.

Smith, Neil, 1984, La producción de la naturaleza, la producción del espacio, Sistema de Universidad Abierta, Facultad de Filosofía y Letras-Universidad Nacional Autónoma de México, México.
Tamayo, Sergio, 2006, "Espacios de ciudadanía, espacios de conflicto", en Sociológica, año 21, núm. 61, Universidad Autónoma Metropolitana-Azcapotzalco, México, pp. 11-40.

, 2008, "Ideología, cultura y hermenéutica de la acción colectiva", en Casa del Tiempo, vol. I, núm. 10, pp. 2-8.

Valenzuela, José Manuel, 1998, El color de las sombras. Chicanos, identidad y racismo, El Colegio de la Frontera Norte, Universidad Iberoamericana, Plaza y Valdés, México.

Velázquez García, Mario A., 2004, "La violencia y los movimientos sociales en el gobierno de Vicente Fox, 2001-2002", en Región y Sociedad, vol. 16, núm. 29, pp. 45-74.

, 2008, "La construcción de un movimiento ambiental en México. El club de golf en Tepoztlán, Morelos", en Región y Sociedad, vol. 20, núm. 43, pp. 61-96.

Unwin, Tim, 1995, El lugar de la geografía, Cátedra, Madrid, pp. 152-181.

Wallerstein, Emmanuel, 2003, “QQué significa hoy ser un movimiento antisistémico?", en Observatorio Social de América Latina, núm. 9, Buenos Aires, pp. 179-184.

Zambrano, Carlos Vladimir, 2003, “Territorios plurales, cambio sociocultural y gobernabilidad cultural", en Beatriz Nates (comp.), Territorio y cultura. Territorios de conflicto y cambio sociocultural, Grupo de Investigación Territorialidades, Universidad de Caldas, Manizales, pp. 18-67.

Zapata, Francisco, 1992, "Premisas de la sociología accionalista”, en Estudios Sociológicos, vol. 10, núm. 29, El Colegio de México, pp. 469-487. 